\title{
Age-Related Modulations in Erythrocytes under Blood Bank Conditions
}

\author{
Carl Hsieh $^{a} \quad$ N.C. Srinivasa Prabhu ${ }^{b}$ Vani Rajashekaraiah ${ }^{a}$ \\ a Department of Biotechnology, School of Sciences, Block I, JAIN (Deemed-to-be University), Bengaluru, India; \\ ${ }^{\mathrm{b}}$ Kempegowda Institute of Medical Sciences (KIMS) Hospital, Bengaluru, India
}

\author{
Keywords \\ Erythrocytes · Oxidative stress · Blood storage . \\ Young and old erythrocytes
}

\begin{abstract}
Background: During storage of erythrocytes, storage lesions are formed that reduce the safety and efficacy of the stored blood. Thus, there is a need to understand the changes that occur during storage. Most studies have focused on storage of a mixed population of erythrocytes. The aim of this study is to analyze the changes in young and old erythrocytes over the course if storage. Materials and Methods: Blood was collected from the blood bank at the Kempegowda Institute of Medical Sciences (KIMS) Hospital (Bengaluru, India) and stored for 35 days in CPDA- 1 at $4{ }^{\circ} \mathrm{C}$. Every 5 days, erythrocytes were separated based on the blood's age using a Percoll-BSA gradient. Young and old erythrocytes obtained were used for analysis of the following oxidative stress (OS) markers: hemoglobin $(\mathrm{Hb})$, hemolysis, mechanical fragility, antioxidant enzymes (superoxide dismutase and catalase [CAT]), superoxides, sialic acid, glutamic oxaloacetate transaminase (GOT), glucose, plasma membrane redox system (PMRS), total antioxidant capacity-cupric ion reducing anti-

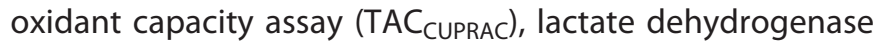
(LDH), lipid peroxidation products (malondialdehyde [MDA] and conjugate dienes), and protein oxidation products (advanced oxidation protein products and protein sulfhydryls). Result: Young cells had higher amounts of $\mathrm{Hb}$, sialic acid,

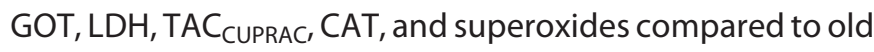
cells. Old cells, however, had higher PMRS and MDA levels with respect to young cells. Discussion: Young cells could endure OS during storage more efficiently than old cells. In
\end{abstract}

conclusion, the efficacy of stored blood depends on the ratio of young cells in the population. This study highlights the prospects of storing young erythrocytes for a prolonged shelf life of blood.

(c) 2019 S. Karger AG, Basel

\section{Introduction}

Erythrocytes are mature red blood cells that are deformable and oval biconcave discs. They are the principal means of transporting $\mathrm{O}_{2}$ and $\mathrm{CO}_{2}$. These cells are enucleate and lack cell organelles. However, they are rich in hemoglobin ( $\mathrm{Hb})$. They have a life span of about 120 days in circulation before they are cleared off [1].

During ageing, changes in physical, biochemical, and physiological properties occur in erythrocytes. The aged cells (old cells) are more likely to be trapped and destroyed during microcirculation [2]. As erythrocytes age, a decrease in cell volume and $\mathrm{Hb}$ is observed. Old erythrocytes also increase in density as they bind to autologous immunoglobulin $\mathrm{G}(\mathrm{IgG})$, that serves as an initiator for the removal of senescent erythrocytes. The binding of antibodies is also associated and triggered by changes to the anion exchanger Band 3, giving rise to neoantigens [3-6]. Over the course of their life span, they have a decreased sulphate transport, which hampers the binding of ankyrin to glyceraldehyde 3-phosphate dehydrogenase (GAPDH), a key enzyme in glycolysis $[7,8]$. There is also an increase in the amount of glycated $\mathrm{Hb}$ [8]. They lose water, 2,3-BPG, ATP, proteins, and $\mathrm{Hb}$, and the number of vesicles increases. Erythrocytes also lose some surface materials such as sialic acids, which alter the structure and

\section{KARGER}

(C) 2019 S. Karger AG, Basel
Dr. Vani Rajashekaraiah

Department of Biotechnology, School of Sciences, Block I

JAIN (Deemed-to-be University)

No. 18/3, 9th Main, 3rd Block, Jayanagar, Bengaluru 560011 (India)

E-Mail vani.rs@ jainuniversity.ac.in 
function of the membrane. These sialic acids are $90 \%$ $\mathrm{N}$-acetylneuraminic acid (NANA), which is responsible for the electrical charge to the cells. These senescent erythrocytes also expose membrane phosphatidylserine [9].

Oxidative stress (OS) occurs when there is an imbalance in the generation of free radicals and reactive oxygen species (ROS) overwhelming the antioxidant capacity. OS causes storage lesions which can be defined as "a series of biochemical and biomechanical changes that occur during storage" [10]. Erythrocytes undergo progressive morphological changes, including deformation of the biconcave disk structures into echinocytes with protrusions and finally into spheroechinocytes. Fragmentation and aggregation of proteins and lipids also occur over the course of storage and are irreversible [11]. Erythrocytes are constantly exposed to OS due to the presence of ROS, which are countered by the endogenous antioxidant system [12].

Few studies have reported the effects of storage on young and old erythrocytes in terms of cell number, intracellular $\mathrm{pH}, \mathrm{CD} 44$ and $\mathrm{CD} 147$, band $4.1 \mathrm{a} / 4.1 \mathrm{~b}$ ratio, etc. [13-16]. However, continuous changes as a function of storage with erythrocyte ageing have not been reported. Thus, the aim of this study is to analyze the effect of storage on young and old sub populations of erythrocytes in whole blood. The changes were analyzed through markers of OS.

\section{Materials and Methods}

Percoll was purchased from GE Healthcare. Epinephrine, thiobarbituric acid (TBA), 4,7-diphenyl-1,10-phenanthrolinedisulfonic acid disodium salt, and bovine serum albumin (BSA) were purchased from Sigma-Aldrich Chemicals (St. Louis, MO, USA), Hemocor-D was purchased from Coral Clinical Systems (India), a glucose kit was purchased from SPAN Diagnostics Ltd. (ARKRAY Healthcare Pvt. Ltd.) and a glutamate oxaloacetate transaminase (GOT) kit was purchased from Aspen Laboratories (India). All other chemicals used were of reagent grade and the organic solvents were of spectral grade.

\section{Blood Sampling}

Blood was obtained from healthy males (volunteer donors) aged 20-45 years from the blood bank at the Kempegowda Institute of Medical Sciences (KIMS) Hospital (Bengaluru, India). The samples were collected before sealing of the blood bags and stored in citrate phosphate dextrose adenine- 1 solution (CPDA-1) solution at $4^{\circ} \mathrm{C}$.

\section{Experimental Design}

Blood was stored at $4{ }^{\circ} \mathrm{C}$ in CPDA- 1 for a period of 35 days. The blood was not leukoreduced. Erythrocytes were isolated from whole blood (each day, $n=20$ ) in 5 -day intervals. The isolated erythrocytes were then separated based on the blood's age using a Percoll density gradient. The young and old erythrocytes obtained were used to assess $\mathrm{Hb}$, hemolysis, and mechanical fragility. They were then converted into hemolysate and the following markers were analyzed: superoxides; sialic acid; antioxidant capacity, i.e., total antioxidant capacity-cupric ion reducing antioxidant capacity assay $\left(\mathrm{TAC}_{\mathrm{CUPRAC}}\right)$, glutathione, and sulfhydryls; plasma mem- brane redox system (PMRS); glucose; lactate dehydrogenase (LDH); antioxidant enzymes; and protein oxidation and lipid peroxidation products.

\section{Erythrocyte Separation}

Erythrocytes were isolated by centrifuging whole blood for 20 min at $1,000 \mathrm{~g}$ at $4{ }^{\circ} \mathrm{C}$. The supernatant (plasma and leukocytes) was discarded and the erythrocytes ( $\mathrm{pRBC}$ ) were washed twice, after which they were resuspended in isotonic phosphate buffer (pH 7.4) (310 imOsm) to a final hematocrit of 50\% [17].

\section{Isolation of Young and Old Erythrocytes}

Young and old erythrocytes were isolated using a modified method of Corsi et al. [18]. In brief, 2 solutions of BSA, i.e., solution 1: $4.8 \%(\mathrm{w} / \mathrm{v})$ BSA in water and solution 2: $4.8 \%(\mathrm{w} / \mathrm{v})$ BSA in Percoll $(1.13 \mathrm{~g} / \mathrm{mL})$, were prepared. Solution A contained 19 parts of solution 1 and 1 part of HEPES buffer ( $\mathrm{pH} 7.4$ ); solution B contained 19 parts of solution 2 and 1 part of HEPES buffer ( $\mathrm{pH} 7.4$ ). Gradients of Percoll concentrations - 84, 76, and 70\% (v/v) - were formed by mixing solutions A and B in the appropriate ratios. By layering each successive gradient carefully, a discontinuous gradient was prepared. The pRBC (50\% hematocrit) were layered upon the gradient carefully and centrifuged at $1,000 \mathrm{~g}$ for $10 \mathrm{~min}$ at $20^{\circ} \mathrm{C}$.

Cells found in the 70\% layer were "young cells," and cells in the 84\% layer were "old cells." These separated erythrocytes were washed and resuspended in isotonic phosphate buffer ( $\mathrm{pH} 7.4)$ to a final hematocrit of $50 \%$. The volumes of the fractions were recorded and the subpopulations were assayed for the OS markers.

\section{Erythrocyte Count}

The numbers of young cells and old cells were counted using a hemocytometer [19]. The numbers of cells were represented as a ratio of young cells to old cells.

\section{Hemolysate Preparation}

Erythrocytes were lysed using hypotonic phosphate buffer yielding hemolysate, which was stored at $-20^{\circ} \mathrm{C}$ for the analyses [17].

\section{Hemoglobin}

Hemocor-D reagent was used to assess the amount of $\mathrm{Hb}$ in the erythrocytes using the cyanomethemoglobin method, and the absorbance was measured at $540 \mathrm{~nm}$. Hb concentrations are shown in grams per deciliter [20].

\section{Oxidative Hemolysis and Mechanical Fragility}

Erythrocyte suspensions (10\%) were divided into 2 groups. Oxidative hemolysis was performed using the method described by Sentürk et al. [21]. Mechanical fragility was performed using the method described by Lippi et al. [22]. Oxidative hemolysis was performed by adding equal volumes of $0.9 \%$ PBS and $1 \% \mathrm{H}_{2} \mathrm{O}_{2}$ into group 1. Mechanical fragility was performed by double aspiration of the erythrocyte suspension through a 1-mL insulin syringe (31 gauge, $0.25 \times 8 \mathrm{~mm})$ and equal volumes of $0.9 \%$ PBS and $1 \% \mathrm{H}_{2} \mathrm{O}_{2}$ were added to group 2. The 2 groups were incubated at $37^{\circ} \mathrm{C}$ in a BOD incubator for $1 \mathrm{~h}$. All of the samples were then centrifuged at $1,000 \mathrm{~g}$ at RT for $5 \mathrm{~min}$. Hemolysis and mechanical fragility were determined by measuring the $\mathrm{Hb}$ released into the supernatant at $540 \mathrm{~nm}$ and represented based on the maximum absorbance $(100 \%)$ in the aliquots of erythrocytes completely hemolyzed in distilled $\mathrm{H}_{2} \mathrm{O}$.

\section{Sialic Acid}

Sialic acid was estimated using the method of Warren [23]. Briefly, the hemolysate was treated with periodate solution and 
incubated at room temperature for $20 \mathrm{~min}$. Arsenite solution was added and vortexed until the brown color disappeared. A solution of $0.6 \% \mathrm{TBA}$ in $0.5 \mathrm{M}$ sodium sulfate was added and incubated in a boiling water bath for $15 \mathrm{~min}$. The reaction mixture was cooled and equal volumes of cyclohexanone were added to the top layer. The mixture was then centrifuged at $1,000 \mathrm{~g}$ for $5 \mathrm{~min}$ and the absorbance of the supernatant was read at $549 \mathrm{~nm}$. The amount of sialic acid present was calculated using the molar extinction coefficient for NANA $\left(57,000 \mathrm{M}^{-1} \mathrm{~cm}^{-1}\right)$.

\section{Glutamate Oxaloacetate Transaminase}

The levels of GOT in hemolysate were assessed utilizing the modified IFCC method spectrophotometrically at $340 \mathrm{~nm}$ as described in the Aspen Laboratories kit [24]. GOT catalyzes the reaction between L-aspartate and $\alpha$-ketoglutarate, forming L-glutamate and oxaloacetate. The oxaloacetate formed reacts with MDH (malate dehydrogenase) to form L-malate and NAD. The rate of NADH-toNAD formation was measured as a decrease in absorbance at 340 $\mathrm{nm}$, which is proportional to the GOT activity in the sample.

\section{Superoxides}

Superoxide levels were estimated by the method of Olas and Wachowicz [25]. Briefly, hemolysate was treated with cytochrome $\mathrm{C}(160 \mu \mathrm{M})$ and incubated at $37^{\circ} \mathrm{C}$. It was then centrifuged at $1,000 \mathrm{~g}$ and the absorbance was measured at $550 \mathrm{~nm}$ (superoxides were represented as $\mu \mathrm{M} / \mathrm{mg}$ protein).

\section{Glucose}

The GOD-POD enzymatic method was used to assess the levels of glucose in hemolysate, as described in the Autospan Gold kit, and the absorbance was measured at $546 \mathrm{~nm}$ [26]. Glucose is oxidized to gluconic acid and $\mathrm{H}_{2} \mathrm{O}_{2}$ in the presence of glucose oxidase. The $\mathrm{H}_{2} \mathrm{O}_{2}$ formed reacts with p-hydrobenzoic acid and 4-aminoantipirine through catalysis by peroxidase, forming a red quinoneimine dye. The intensity of the red color is proportional to the amount of glucose present.

\section{Lactate Dehydrogenase}

The LDH in the hemolysate was measured using the method of Buhl et al. [27]. Briefly, the hemolysate was treated with the LDH reagent (a mixture of reagents 1 [ $80 \mathrm{~mm}$ Tris, $1.6 \mathrm{~mm}$ pyruvate, and $200 \mathrm{mM} \mathrm{NaCl}]$ and $2[0.2 \mathrm{mM} \mathrm{NADH}]$ at a ratio of 4:1) and incubated at $37^{\circ} \mathrm{C}$ for $5 \mathrm{~min}$. The absorbance was measured at $340 \mathrm{~nm}$.

\section{Glutathione}

Glutathione was measured using the method described by Beutler et al. [28]. Briefly, hemolysate was treated with $4 \%$ sulfosalicylic acid, vortexed, and centrifuged at $2,500 \mathrm{~g}$ for $15 \mathrm{~min}$. The su-

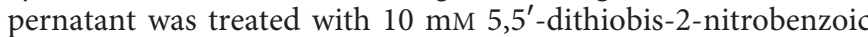
acid (DTNB) and the absorbance was read at $412 \mathrm{~nm}$.

\section{Total Antioxidant Capacity-Cupric Ion Reducing Antioxidant} Capacity Assay

TAC $\mathrm{C}_{\text {CUPRAC }}$ was measured using the method described by Da Cruz [29]. Briefly, the hemolysate was treated with $0.25 \mathrm{mM}$ BCS in $10 \mathrm{mM}$ phosphate buffer ( $\mathrm{pH} 7.4$ ) and an initial absorbance was read at $490 \mathrm{~nm}$. After the addition of $0.5 \mathrm{mM} \mathrm{CuSO}_{4}$, it was incubated at room temperature for $3 \mathrm{~min}$. Ethylenediaminetetraacetic acid (EDTA) $(0.01 \mathrm{M})$ was added to arrest the reaction and the absorbance was read at $490 \mathrm{~nm}$. The results were compared with a standard uricacid curve (and are expressed in mMuricacid equivalents/L).

Plasma Membrane Redox System

The erythrocyte trans-plasma membrane redox activity was estimated by following the reduction of ferricyanide according to a modified method of Avron and Shavit [30]. The hemolysate was mixed with PBS (containing $5 \mathrm{mM}$ glucose and $1 \mathrm{mM}$ potassium ferricyanide) and incubated for $30 \mathrm{~min}$ at $37^{\circ} \mathrm{C}$ and then centrifuged at $1,800 \mathrm{~g}$ at $4^{\circ} \mathrm{C}$. The supernatant was assayed for ferrocyanide content using 4,7-diphenyl-1,10-phenanthrolinedisulfonic acid disodium salt and absorption was measured at $535 \mathrm{~nm}(\mathrm{e}=$ $20,500 \mathrm{M}^{-1} \mathrm{~cm}^{-1}$ ) (results are expressed as $\mu \mathrm{mol}$ ferrocyanide/mL hemolysate/30 $\mathrm{min})$.

\section{Antioxidant Enzymes}

Superoxide Dismutase

Superoxide dismutase (SOD) activity was measured using the method described by Misra and Fridovich [31]. In brief, the hemolysate was treated with carbonate buffer $(0.05 \mathrm{M})$ and epinephrine (30 mM). The change in absorbance was monitored spectrophotometrically at $480 \mathrm{~nm}$. SOD activity was expressed as the amount of enzyme that inhibits $50 \%$ oxidation of epinephrine.

\section{Catalase}

Catalase (CAT) activity was measured according to the method described by Aebi [32]. Briefly, the hemolysate was treated with absolute alcohol and incubated at $0{ }^{\circ} \mathrm{C}$. To this reaction mixture, $\mathrm{H}_{2} \mathrm{O}_{2}(6.6 \mathrm{mM})$ and phosphate buffer were added and the reduction in absorbance was detected spectrophotometrically at $240 \mathrm{~nm}$. The enzyme activity was estimated using an extinction coefficient of $43.6 \mathrm{M} \mathrm{cm}^{-1}$

\section{Lipid Peroxidation}

Malondialdehyde

Malondialdehyde (MDA) was measured according to the method described by Ohkawa et al. [33]. In brief, hemolysate was mixed with SDS $(8.1 \%)$, acetic acid (20\%), and TBA $(0.6 \%)$ and incubated at $100{ }^{\circ} \mathrm{C}$. The samples were cooled and treated with butanol-pyridine (15:1) mixture. The absorbance of the supernatant was measured at $532 \mathrm{~nm}$ using the standard, i.e., 1,1,3,3-tetramethoxy propane (MDA levels were represented as $\mu \mathrm{mol} / \mathrm{mg}$ protein).

\section{Conjugate Dienes}

Conjugate dienes was measured by the method described by Olas and Wachowicz [25]. Briefly, hemolysate was treated with ether:ethanol [1:3 (v/v)], vortexed, and centrifuged at 6,000g. The level of conjugate dienes was measured in the supernatant at 235 $\mathrm{nm}$.

\section{Protein Oxidation}

\section{Advanced Oxidation Protein Products}

Advanced oxidation protein products (AOPP) were measured according to Witko et al. [34]. In brief, hemolysate was treated with isotonic phosphate buffer, $1.16 \mathrm{M}$ potassium iodide, and glacial acetic acid. The absorbance was measured at $340 \mathrm{~nm}$. The amount of AOPP was estimated using an extinction coefficient of $26 \mathrm{mM}^{-1} \mathrm{~cm}^{-1}$.

Protein Sulfhydryls

The hemolysate was treated with sodium phosphate buffer $(0.08$ M) with $\mathrm{Na}_{2}$-EDTA $(0.5 \mathrm{mg} / \mathrm{mL})$ and SDS (2\%). DTNB $(20 \mathrm{mg}$ in $10 \mathrm{~mL}$ ) was added and the reaction mixture was incubated at room temperature. The absorbance was measure spectrophotometrically at $412 \mathrm{~nm}$. The amount of protein sulfhydryls (P-SH) was determined using a molar absorptivity, of $13,600 \mathrm{M}^{-1} \mathrm{~cm}^{-1}$ [35].

\section{Protein Determination}

Protein in the samples were determined with the standard, i.e., BSA [36]. 
Table 1. Oxidative hemolysis, mechanical fragility, and LDH in young and old erythrocytes in stored blood

\begin{tabular}{|c|c|c|c|c|c|c|}
\hline \multirow[t]{2}{*}{$\begin{array}{l}\text { Storage time, } \\
\text { days }\end{array}$} & \multicolumn{2}{|c|}{$\begin{array}{l}\text { Oxidative hemolysis, } \\
\% \text { hemolysis }\end{array}$} & \multicolumn{2}{|c|}{$\begin{array}{l}\text { Mechanical fragility, } \\
\% \text { hemolysis }\end{array}$} & \multicolumn{2}{|c|}{$\begin{array}{l}\mathrm{LDH} \text {, } \\
\mathrm{U} / \mathrm{mg} \text { protein } \times 10^{-3}\end{array}$} \\
\hline & young cells ${ }^{\mathrm{a}}$ & old cells ${ }^{\mathrm{a}}$ & young cells ${ }^{\mathrm{a}}$ & old cells ${ }^{\mathrm{b}}$ & young cells ${ }^{\mathrm{a}}$ & old cells ${ }^{\mathrm{a}}$ \\
\hline 0 & $18.06 \pm 6.12$ & $25.5 \pm 5.83$ & $46.88 \pm 6.54$ & $27.41 \pm 2.65$ & $31.88 \pm 5.34$ & $22.67 \pm 5.09$ \\
\hline 5 & $19.01 \pm 6.64$ & $27.118 \pm 7.17$ & $47.97 \pm 5.35$ & $29.98 \pm 3.17$ & $33.12 \pm 5.38$ & $26.14 \pm 5.86$ \\
\hline 10 & $21.3 \pm 2.91$ & $34.3 \pm 10.6$ & $78.42 \pm 2.4^{*} \#$ & $33.23 \pm 3.49$ & $41.59 \pm 5.08$ & $32.63 \pm 8.2$ \\
\hline 15 & $28.89 \pm 6.24$ & $33.04 \pm 4.47$ & $69.86 \pm 2.87^{*, \#}$ & $30.91 \pm 2.8$ & $42.23 \pm 5.21$ & $56.21 \pm 8.35^{*}$ \\
\hline 20 & $48.81 \pm 41.5$ & $63.42 \pm 13.41^{*, \#}$ & $53.05 \pm 3.45^{* *}$ & $34.07 \pm 3.64$ & $41.5 \pm 5.96$ & $63.55 \pm 8.72^{*, \#, * *}$ \\
\hline 25 & - & $35.81 \pm 11.4$ & - & $36.79 \pm 3.53$ & - & $23.22 \pm 3.46^{\# \#, \cdot}$ \\
\hline 30 & - & $14.39 \pm 4.49^{\prime}$ & - & $38.3 \pm 4.06$ & - & $20.78 \pm 4.84^{\# \#, \cdot}$ \\
\hline 35 & - & $16.15 \pm 5.58^{\prime \prime}$ & - & $41.45 \pm 3.03$ & - & $21.95 \pm 4.08^{\# \#, \cdot}$ \\
\hline
\end{tabular}

Values are presented as means \pm SE. Changes between cell ages are represented by lowercase letters. Changes within the groups (storage) are represented by special characters. * Significant compared to day 0 . \# Significant compared to day $5 .{ }^{* *}$ Significant compared to day 10. \#\# Significant compared to day 15. - Significant compared to day 20. Those not sharing the same letters are significantly different. Significance level: oxidative hemolysis and mechanical fragility: storage $(p<0.001)$; LDH: storage and between cell ages $(p<$ $0.0001)$.

Statistical Analyses

The results obtained were expressed as means \pm SE. Two-way ANOVA and a Bonferroni post-hoc test was performed using GraphPad Prism 6 software, and $p<0.05$ was considered statistically significant.

\section{Results}

Young erythrocytes could be isolated until day 20 . Cells were not present in the $70 \%$ Percoll layer after day 20 . The fraction of young cells decreased by $60 \%$ on day 5 and by $30 \%$ from day 10 onwards when compared with day 0 , respectively. However, the old cell fraction was reduced by $30 \%$ only on day 5 when compared with day 0 . The variations in the volumes of old erythrocytes were insignificant from day 5 .

\section{Erythrocyte Count}

The ratio of young:old cells was reduced over the storage period. The ratio in earlier days of storage (days 0 and 5) was 1.5 and from day 10 onwards it was reduced to 0.9 .

\section{Hemoglobin}

Hb was significant $(p<0.0001)$ on all days with respect to storage in young and old erythrocytes. Hb increased on days 10 and 15 with respect to day 0 in the young cells. Decrements in $\mathrm{Hb}$ were observed on day 20 compared to days 10 and 15 , respectively.

$\mathrm{Hb}$ incremented on day 25 compared to days $0,5,10$, and 20 respectively, while a decrement was observed on day 35 compared to day 25 in old cells.
Hb was significant $(p<0.001)$ between young and old erythrocytes. Decrements in Hb were observed in old cells with respect to young cells on days 10 and 15 , respectively.

\section{Oxidative Hemolysis}

Oxidative hemolysis was significant on all days with storage in old cells $(p<0.001)$. A 1 -fold increment was observed on day 20 compared to days 0 and 5 , while a decrement of $75 \%$ was observed on days 30 and 35 compared to day 20 in old cells. Hemolysis was insignificant between young and old cells (Table 1).

\section{Mechanical Fragility}

Significant changes $(p<0.001)$ in mechanical fragility were observed with respect to storage in old cells. Oneand 2-fold increments were observed on days 15 and 20 compared to day 0 in old cells. Mechanical fragility was elevated by 1 -fold on day 20 compared to days 5 and 10 , respectively. Decrements were observed on days 25,30 , and 35 when compared with days 15 and 20.

Mechanical fragility was significant $(p<0.001)$ between young and old erythrocytes. A decrement was observed in young cells with respect to old cells on day 20 (Table 1).

\section{Sialic Acid}

Changes in sialic acid were insignificant with storage. A decrement was observed on day 0 between young and old cells (Fig. 1).

\section{Glutamic Oxaloacetate Transaminase}

Changes in glutamic oxaloacetate transaminase (GOT) were significant $(p<0.01)$. A decrement in GOT was observed in old cells when compared with young cells on day 0 . 
Fig. 1. Sialic acid in young and old erythrocytes of stored blood. Values are presented as means \pm SE. Changes between cell ages were significant at $p<0.001$. Changes within the groups (storage) were insignificant.

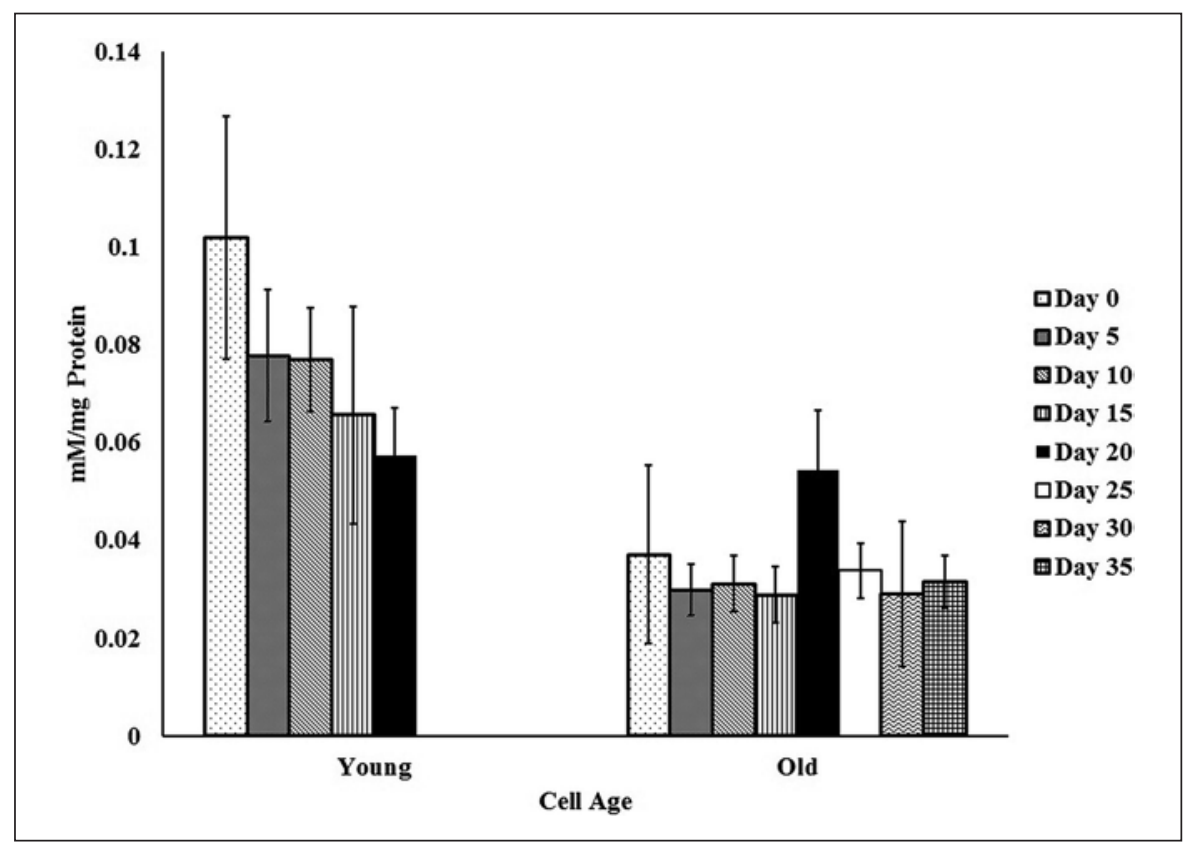

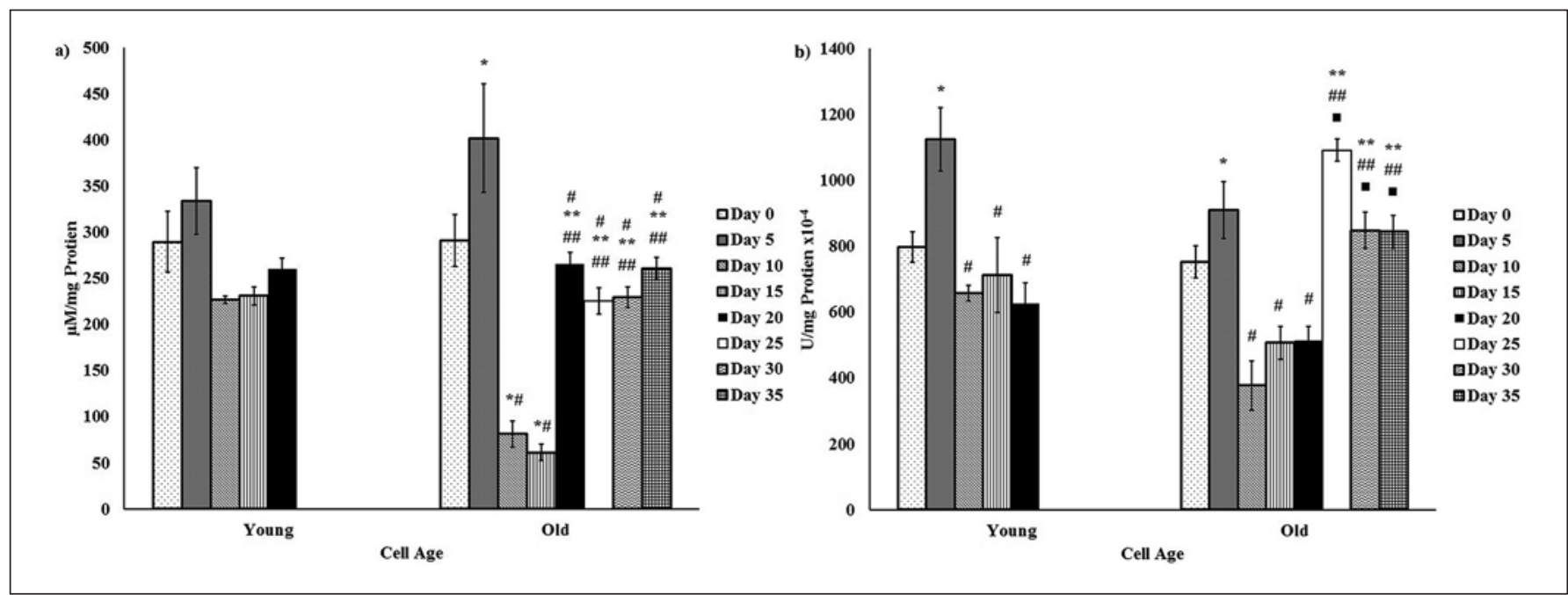

Fig. 2. Superoxide (a) and CAT (b) in young and old erythrocytes of stored blood. Values are presented as means \pm SE. Changes between cell ages were significant for superoxide at $p<0.01$. Changes within groups (storage) were significant for superoxide $(p<$

\section{Superoxides}

Changes in superoxides were significant $(p<0.0001)$ in old cells during storage. An increment was observed on day 5 , while decrements were observed on days 10 and 15 compared to day 0 in old cells. Decrements on days 10 , $15,20,25,30$, and 35 were observed when compared with day 5. Elevations of 2-fold were observed on days 20, 25, 30 , and 35 with respect to days 10 and 15 .

Superoxides were significant $(p<0.01)$ between young and old erythrocytes. Decrements in superoxides were
$0.0001)$ and CAT $(p<0.001) .{ }^{*}$ Significant compared to day 0 . \# Significant compared to day 5. ${ }^{* *}$ Significant compared to day 10. \#\# Significant compared to day 15. Significant compared to day 20.

observed on days 10 and 15 in old cells with respect to young cells (Fig. 2).

\section{Glucose}

Changes in glucose were insignificant with respect to storage in all of the groups. The glucose level was higher in young cells than old cells. A decrement was observed in old cells compared to young cells on day 15 . 
Fig. 3. PMRS in young and old erythrocytes in stored blood. Values are presented as means \pm SE. Changes between cell ages were significant at $p<0.0001$. Changes within groups (storage) were significant at $p<0.0001 . *$ Significant compared to day 0 . \# Significant compared to day 5 . ** Significant compared to day 10. \#\# Significant compared to day 15. Significant compared to day 20 .

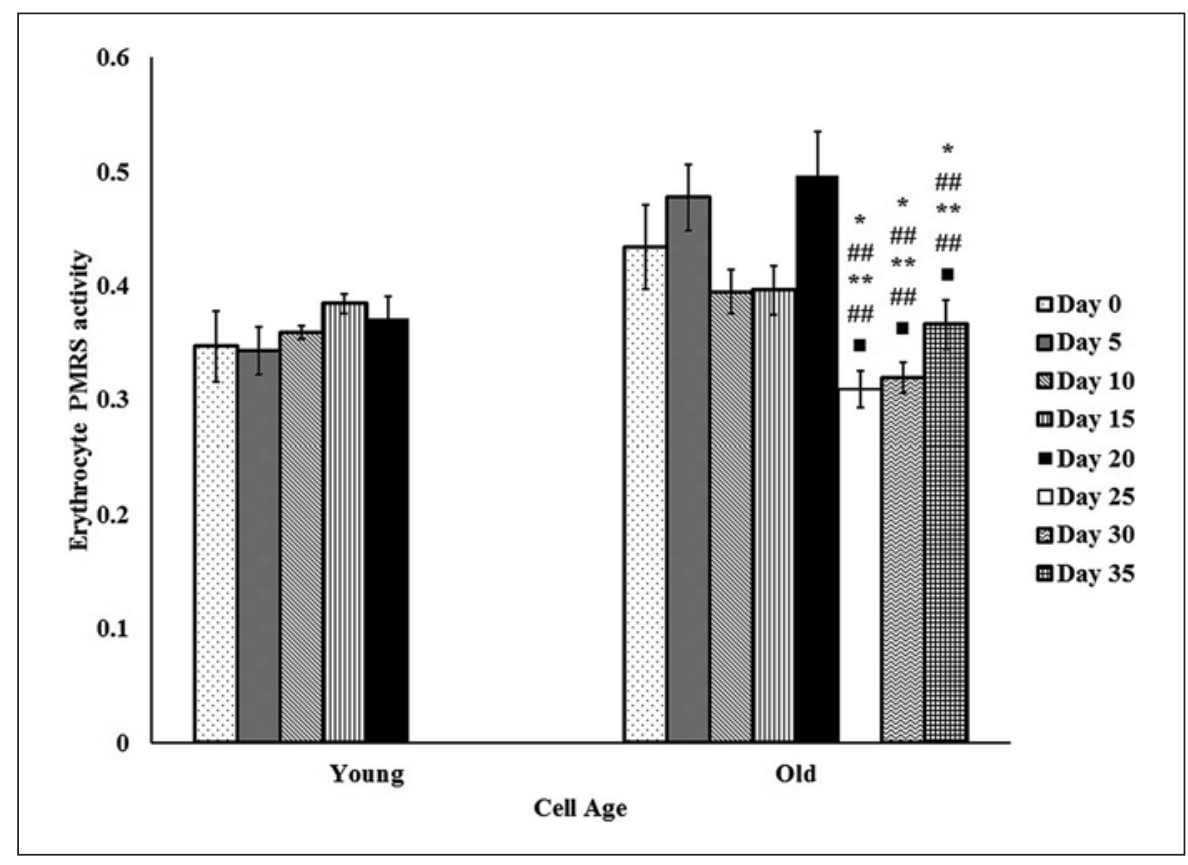

Table 2. $\mathrm{TAC}_{\mathrm{CUPRAC}}$, glutathione, and $\mathrm{P}-\mathrm{SH}$ in young and old erythrocytes in stored blood

\begin{tabular}{|c|c|c|c|c|c|c|}
\hline \multirow[t]{2}{*}{$\begin{array}{l}\text { Storage } \\
\text { time, days }\end{array}$} & \multicolumn{2}{|c|}{$\begin{array}{l}\mathrm{TAC}_{\text {CUPRAC, }} \\
\mu \mathrm{M} \text { uric acid equivalents/L }\end{array}$} & \multicolumn{2}{|l|}{$\begin{array}{l}\text { Glutathione, } \\
\mu \mathrm{M} / \mathrm{mg} \text { protein }\end{array}$} & \multicolumn{2}{|l|}{$\begin{array}{l}\mathrm{P}-\mathrm{SH}, \\
\mu \mathrm{M} / \mathrm{mg} \text { protein }\end{array}$} \\
\hline & young cells ${ }^{\mathrm{a}}$ & old cells ${ }^{\mathrm{b}}$ & young cells ${ }^{\mathrm{a}}$ & old cells $\mathrm{a}^{\mathrm{a}}$ & young cells ${ }^{\mathrm{a}}$ & old cells ${ }^{\mathrm{a}}$ \\
\hline 0 & $1,831.27 \pm 141.97$ & $1,394.87 \pm 96.3$ & $118.54 \pm 15.79$ & $84.42 \pm 12.49$ & $119.2 \pm 20.83$ & $144.15 \pm 12.75$ \\
\hline 5 & $1,814.44 \pm 111.23$ & $1,331.531 \pm 83.9$ & $111.52 \pm 15.36$ & $111.03 \pm 18.05$ & $161.33 \pm 25.5$ & $168.75 \pm 21.14$ \\
\hline 10 & $2,353 \cdot 93 \pm 57.29^{*, \#}$ & $1,593.68 \pm 227.27$ & $19.28 \pm 1.62^{*, \#}$ & $35.24 \pm 6.19^{\#}$ & $172.38 \pm 7.2$ & $181.6 \pm 9.03$ \\
\hline 15 & $1,931.82 \pm 88.21$ & $1,613.85 \pm 134.06$ & $16.59 \pm 2.94^{*, \#}$ & $21.34 \pm 2.45^{*, \#}$ & $173.79 \pm 10.03$ & $151 \pm 11.34$ \\
\hline 20 & 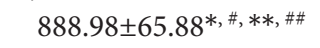 & $1,138.28 \pm 73.48$ & $117.04 \pm 6.85^{* *, \# \#}$ & $146.36 \pm 13.51^{*, * *, \# \#}$ & $177.33 \pm 12.56$ & $154.92 \pm 19.18$ \\
\hline 25 & - & $1,790.58 \pm 101^{\circ}$ & - & $35.63 \pm 11.64^{\circ}$ & - & $196.86 \pm 9.2$ \\
\hline 30 & - & $1,377.33 \pm 72.04$ & - & 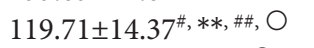 & - & $105.48 \pm 13.17^{* *}, \bigcirc$ \\
\hline 35 & - & $1,392.56 \pm 76.31$ & - & 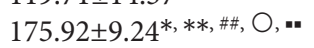 & - & $133.24 \pm 14.93 \bigcirc$ \\
\hline
\end{tabular}

Values are presented as means \pm SE. Changes between cell ages $(p<0.0001)$ are represented by lowercase letters. Changes within the groups (storage) were significant at $p<0.0001$ and are represented by special characters. ${ }^{*}$ Significant compared to day 0. \# Significant compared to day 5. ** Significant compared to day 10. \#\# Significant compared to day 15. - Significant compared to day 20. $\bigcirc$ Significant compared to day 25. Those not sharing the same letters are significantly different.

\section{Lactate Dehydrogenase}

Changes in LDH were significant $(p<0.0001)$ with respect to storage in young cells. Elevations in LDH were observed on days 10 and 15 in the young cells compared to days 0 and 5. A decrement was observed on day 20 compared to day 10 (Table 1).

LDH was significant $(p<0.0001)$ between young and old erythrocytes. LDH decreased on days $0,5,10,15$, and 20 in old cells compared to young cells.

\section{Glutathione}

Significant changes $(p<0.0001)$ in glutathione were observed with storage in young and old cells. Decrements in glutathione were observed on days 10 and 15 when compared with days 0 and 5 in young cells. Glutathione also elevated by 5 -fold (day 20 vs. day 10 ) and 6 -fold (day 20 vs. day 15).

Glutathione decreased on day 15, while it increased on days 20 and 35 compared with day 0 in old cells. Decrements on days 10, 15, and 25 and an increment on day 35 were observed compared to day 5. Glutathione increased by 2-, 3-, and 4-fold and by 5-, 6-, and 7-fold on days 30, 20, 


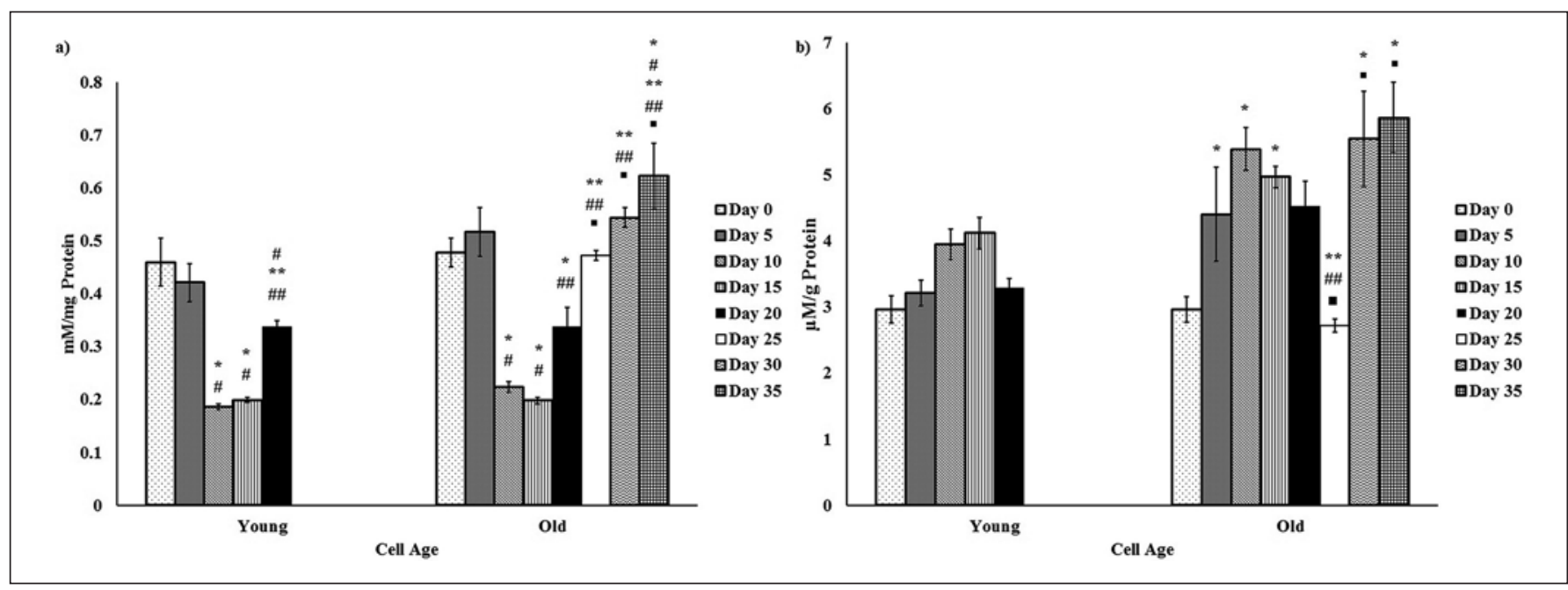

Fig. 4. Lipid peroxidation products, i.e., conjugate dienes (a) and MDA (b), in young and old erythrocytes in stored blood. Values are presented as means \pm SE. Changes between cell ages were significant in MDA at $p<0.0001$. Changes within groups (storage) were significant in conjugate dienes $(p<0.0001)$ and MDA $(p<$ 0.01). * Significant compared to day $0 .{ }^{*}$ Significant compared to day 5. ** Significant compared to day 10. ${ }^{\#}$ Significant compared to day 15. Significant compared to day 20. and 35 versus days 10 and 15 . respectively. A decrement was observed on day 25 compared to day 20 . Increments of 2 -fold (day 30 ) and 4-fold (day 35) were observed versus day 25. Glutathione increased on day 35 compared to day 30. Changes between cell ages were insignificant (Table 2).

Total Antioxidant Capacity-Cupric Ion Reducing Antioxidant Capacity Assay

Changes in TAC CUPRAC $_{\text {were significant }}(p<0.0001)$ with storage in young and old cells. It was elevated on day 10 and declined on day 20 compared to days 0 and 5 in young cells. $\mathrm{TAC}_{\text {CUPRAC }}$ reduced on day 20 compared to days 10 and 15 , respectively. Significant changes $(p<0.0001)$

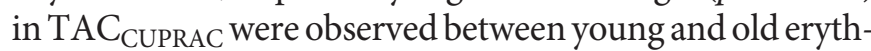
rocytes. Decrements were observed on days 5 and 10 in old erythrocytes when compared with young ones (Table 2).

\section{Plasma Membrane Redox System}

Changes in PMRS were significant $(p<0.0001)$ during storage in old cells. Reductions on days 25 and 30 were observed compared to day 0 in old cells. An increment was observed on day 20 compared to days 10 and 15, respectively. PMRS declined on days 25,30 , and 35 compared to day 20.

Significant changes $(p<0.0001)$ in PMRS were observed between young and old erythrocytes. PMRS was elevated on days 5 and 20 in old cells when compared with young cells (Fig. 3).

\section{Superoxide Dismutase}

Changes in SOD were significant $(p<0.0001)$ with storage in young and old cells. An elevation in SOD was observed on day 20 compared to days 5 and 15 in young cells. SOD increased on day 20 compared to day 10 . SOD decreased in old cells on day 25 compared to day 5 . Variations in SOD were insignificant between young and old erythrocytes.

\section{CAT}

CAT was significant $(p<0.001)$ in young and old cells with storage. An elevation was observed on day 5 with respect to day 0 in young cells. Decrements in CAT on days 10,15 , and 20 were observed against day 5 .

A decline in CAT was observed on day 10 compared to day 0 in old cells. Decrements on days 10, 15, and 20 were observed compared to day 5. CAT increased by 2 -fold (day 25) and 1-fold (days 30 and 35) versus day 10. Elevations of 1 -fold (day 25) and 66\% (days 30 and 35) were observed when compared to days 15 and 20.

Significant changes $(p<0.01)$ in CAT were observed between young and old cells. CAT decreased on day 10 in old cells versus young cells (Fig. 2).

\section{Malondialdehyde}

Variations in MDA were significant $(p<0.01)$ with storage in old erythrocytes. Elevations in MDA were observed on days $10,15,30$, and 35 , respectively, versus day 0 in old cells. MDA decreased on day 25 compared with days 10, 15, and 20, respectively. An increments of 1-fold was observed on days 30 and 35 compared to day 25 .

The MDA change was significant $(p<0.0001)$ between young and old erythrocytes. An elevation in MDA was observed on days 10 and 20 in old cells compared to young ones (Fig. 4). 


\section{Conjugate Dienes}

Changes in conjugate dienes were significant $(p<$ 0.0001 ) in young and old cells. Conjugate dienes decremented on days 10 and 15 compared to days 0 and 5 in young cells. Elevations in conjugate dienes were observed on day 20 compared to days 10 and 15 , respectively.

Conjugate dienes decreased on days 10 and 15 but increased on day 35 compared to day 0 in old cells. Increments of 1 -fold (days 25 and 30 ) and 2-fold (day 35) were observed compared to days 10 and 15 , respectively. Increments in conjugate dienes were observed on days 25,30 , and 35 compared to day 20 . An elevation was observed on day 35 compared to day 25 . Conjugate dienes were insignificant between the age groups (Fig. 4).

\section{Advanced Oxidation Protein Products}

Changes in AOPP were significant $(p<0.0001)$ with storage in young and old cells. An increment in AOPP was observed on day 20 compared to days $0,5,10$, and 15 in young cells.

AOPP increased on day 20 compared to days $0,5,10$, and 15 in old cells. Decrements in AOPP were observed on days 25,30 , and 35 compared with day 20 . AOPP was insignificant between young and old erythrocytes.

\section{Protein Sulfhydryls}

Variations in P-SH were significant $(p<0.0001)$ with storage in old cells. Decrements in P-SH were observed on day 30 compared to days 10 in old cells. P-SH decreased on days 30 and 35, respectively, compared to day 25. Sulfhydryls were insignificant with respect to cell age (Table 2).

\section{Discussion}

ROS causes oxidative damage to erythrocytes which result in reduced functionality and efficacy of the cells. This causes premature removal of erythrocytes from circulation, leading to a reduced life span of mainly old cells but sometimes even young cells [37]. The samples were restricted to a young population (age 20-45 years) as samples collected from aged individuals have been reported to have a reduced life span [38]. The samples were also restricted to males to eliminate the effects of hormones such as estrogen and progesterone, which are found in higher concentrations in females [39].

Sialic acids (90\% NANA) are responsible for the electrical charge of the cells [9]. Young erythrocytes have a higher sialic acid content compared to old ones [24]. This was evident in our study, where young cells had higher amounts of sialic acid. GOT, also known as aspartate transaminase (AST) reversibly catalyzes the transfer of amino groups between aspartate and glutamate and plays a key role in amino acid metabolism. It is an age index in erythrocytes, where old erythrocytes have lower GOT levels compared to young ones [24]. Similar results were observed in our study, where young cells had higher GOT levels than old cells. The results of sialic acid and GOT indicate that the cells present in the $70 \%$ Percoll layer comprise mainly young cells and, at $84 \%$, old cells.

Previous studies have reported that young cells are absent during prolonged storage (more than 21 days). Young and old cells progressively decline with storage time. The ratio of young to old erythrocytes also decreased [16]. Similar results were observed in our study as erythrocytes disappeared in the $70 \%$ Percoll gradient from day 25 and the ratio of young to old cells decreased as storage progressed.

Generation of vesicles results in a significant amount of $\mathrm{Hb}$ being lost during storage and ageing of erythrocytes [8]. Similar results were observed in our study, where $\mathrm{Hb}$ decreased over the course of storage and was higher in young cells than in old cells.

Erythrocytes undergo progressive morphological changes over the course of storage, leading to hemolysis [12]. Old cells have higher hemolysis and mechanical fragility as the shape recovery after membrane deformation in slower compared to young cells [40]. This was in accordance with our results, where old cells had higher hemolysis and osmotic fragility. However, hemolysis and mechanical fragility increased in both young and old cells during storage. The limitation of this study is that oxidative hemolysis was measured and storage hemolysis was not analyzed.

Enzyme activity decreases with cell age. Young cells have a higher metabolic rate than old cells [41]. This was reiterated in our results, where glucose and LDH were higher in young erythrocytes.

The role of PMRS in maintaining intracellular redox balance in erythrocytes is limited, since they lack mitochondria [42]. However, PMRS protects the erythrocytes against OS and an increase in PMRS represents an increase in OS [43]. The increase in PMRS in old cells is indicative of higher OS and reduction in antioxidant potential. The reduction of PMRS in old cells towards the end of storage can be attributed to the reduction in cell number, as a reduction in PMRS triggers apoptosis [44]

Superoxides are formed along with methemoglobin during the dissociation of oxyhemoglobin. Superoxides are highly toxic and they trigger the ROS cascade in erythrocytes [45]. Superoxides were maintained during the storage period in both groups. However, the decline in superoxides in old cells on days 10 and 15 can be attributed to the decrease in glutathione. Glutathione peroxidase is the first line of defense and acts at lower concentrations of $\mathrm{H}_{2} \mathrm{O}_{2}$, while CAT acts at higher concentrations, which is reflected in the CAT activity during late 
storage [46]. Antioxidant enzymes (SOD and CAT) were maintained even though superoxide levels increased towards the end of storage. This may be due to the effective endogenous antioxidant system of erythrocytes. CAT activity was lower on days 10,15, and 20 and increased towards the end of storage in old cells. This can be due to lower superoxide levels, leading to a reduced $\mathrm{H}_{2} \mathrm{O}_{2}$ formation in earlier storage days.

Young cells had higher a total antioxidant capacity as

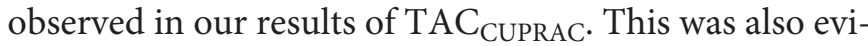
dent in the results of antioxidant enzymes and glutathione. The reduction in glutathione on days 10 and 15 can be attributed to the maximum ROS being produced on those days [47].

Lipid peroxidation results in the formation of hydroperoxides and endoperoxides. Upon fragmentation, these yield reactive carbonyl species such as MDA [46]. Conjugate dienes are primary products of peroxidation and are converted to other forms. They were higher on the initial days and reduced with storage. Young cells had lower levels of MDA than old cells, as MDA accumulates in senescent erythrocytes [48]. Conjugate dienes and MDA were inversely proportional as storage progressed. Previous studies have confirmed that the ROS level is maximal on days 15 and 20 [47]. This was also observed in our results, where MDA increased with ROS. The reduction in MDA on day 25 can be attributed to MDA being a highly reactive electrophile species, forming protein adducts (advanced glycation end products) since the ROS was at a maximum.

Proteins are highly susceptible to oxidative damage due to their rapid reaction rate with radicals and oxidants, resulting in a loss of function [49]. Protein oxidation increases over the course of storage [50], which was also observed in both young and old cells. This was in cor- roboration with our results of lipid peroxidation and PMRS. However, changes between young and old cells were insignificant.

Young erythrocytes had higher amounts of $\mathrm{Hb}$, sialic acid, GOT, LDH, and TAC CUPRAC $_{\text {when compared to old }}$ cells. However, PMRS and MDA were higher in old erythrocytes with respect to young ones. Thus, young erythrocytes could endure OS more efficiently than old erythrocytes.

In conclusion, the efficacy of stored blood depends on the ratio of young cells in the population. This study highlights the prospects of storing young erythrocytes to improve the shelf life of blood.

\section{Acknowledgement}

The authors acknowledge Dr. Leela Iyengar, Dr. S.H. Manohar, Ms. Soumya Ravikumar, Mrs. K. Manasa, and JAIN (Deemed-tobe University) for their support. The authors would also like to acknowledge the award of JAIN (Deemed-to-be University) fellowship to Mr. Carl Hsieh. We are grateful to Dr. Venkatesh Prasad, blood bank officer at KIMS Hospital, for his cooperation towards sample collection. We also acknowledge the support of Dr. Suma, Head of the Department of Medical Electronics, BMS Engineering College (Bengaluru, India).

\section{Statement of Ethics}

Ethical approval for this study was obtained from the Ethics Committee of KIMS Hospital.

\section{Disclosure Statement}

The authors have no conflict of interests to disclose.

\section{References}

1 Pandey KB, Rizvi SI. Biomarkers of oxidative stress in red blood cells. Biomed Pap Med Fac Univ Palacky Olomouc Czech Repub. 2011 Jun; 155(2):131-6.

2 Nash GB, Wyard SJ. Changes in surface area and volume measured by micropipette aspiration for erythrocytes ageing in vivo. Biorheology. 1980;17(5-6):479-84.

3 Belo L, Rebelo I, Castro EM, Catarino C, Pereira-Leite L, Quintanilha A, et al. Band 3 as a marker of erythrocyte changes in pregnancy. Eur J Haematol. 2002 Sep;69(3):14551.

4 Bosman GJ, Willekens FL, Werre JM. Erythrocyte aging: a more than superficial resemblance to apoptosis? Cell Physiol Biochem. 2005; 16(1-3):1-8

5 Ciccoli L, Rossi V, Leoncini S, Signorini C, Blanco-Garcia J, Aldinucci C, et al. Iron release, superoxide production and binding of autologous IgG to band 3 dimers in newborn and adult erythrocytes exposed to hypoxia and hypoxia-reoxygenation. Biochim Biophys Acta. 2004 Jun;1672(3):203-13.

6 Rossi V, Leoncini S, Signorini C, Buonocore G, Paffetti P, Tanganelli D, et al. Oxidative stress and autologous immunoglobulin $\mathrm{G}$ binding to band 3 dimers in newborn erythrocytes. Free Radic Biol Med. 2006 Mar;40(5):907-15.

7 Kay M. Immunoregulation of cellular life span. Ann N Y Acad Sci. 2005 Dec;1057(1):85-111.

8 Bosman GJ, Werre JM, Willekens FL, Novotný VM. Erythrocyte ageing in vivo and in vitro: structural aspects and implications for transfusion. Transfus Med. 2008 Dec;18(6):335-47.

9 Huang YX, Wu ZJ, Mehrishi J, Huang BT, Chen XY, Zheng XJ, et al. Human red blood cell aging: correlative changes in surface charge and cell properties. J Cell Mol Med. 2011 Dec;15(12):2634-42.
10 Ghasemzadeh A, Jaafar HZ. Rahmat: antioxidant activities, total phenolics and flavonoids content in two varieties of Malaysia young ginger (Zingiberofficinale Roscoe). Molecules. 2010;15:4323-33.

11 Rajashekharaiah V, Koshy AA, Koushik AK, Kaur H, Kumari K, Agrawal M, et al. The efficacy of erythrocytes isolated from blood stored under blood bank conditions. Transfus Apheresis Sci. 2012 Dec;47(3):359-64.

12 Marar T. Amelioration of glucose induced hemolysis of human erythrocytes by vitamin E. Chem Biol Interact. 2011 Sep;193(2):14953.

13 Minetti G, Ciana A, Profumo A, Zappa M, Vercellati C, Zanella A, et al. Cell age-related monovalent cations content and density changes in stored human erythrocytes. Biochim Biophys Acta. 2001 Aug;1527(3):14955. 
14 Sparrow RL, Healey G, Patton KA, Veale MF. Red blood cell age determines the impact of storage and leukocyte burden on cell adhesion molecules, glycophorin A and the release of annexin V. Transfus Apheresis Sci. 2006 Feb;34(1):15-23.

15 Sparrow RL, Veale MF, Healey G, Payne KA. Red blood cell (RBC) age at collection and storage influences RBC membrane-associated carbohydrates and lectin binding. Transfusion. 2007 Jun;47(6):966-8

16 Tuo WW, Wang D, Liang WJ, Huang YX. How cell number and cellular properties of blood-banked red blood cells of different cell ages decline during storage. PLoS One. 2014 Aug;9(8):e105692.

17 Dodge JT, Mitchell C, Hanahan DJ. The preparation and chemical characteristics of hemoglobin-free ghosts of human erythrocytes. Arch Biochem Biophys. 1963 Jan;100(1):119-30.

18 Corsi D, Paiardini M, Crinelli R, Bucchini A, Magnani M. Alteration of $\alpha$-spectrin ubiquitination due to age-dependent changes in the erythrocyte membrane. Eur J Biochem. 1999 May;261(3):775-83.

19 Hesser EF. Methods for routine fish hematology. Prog Fish Cult. 1960;22(4):164-71.

20 Hawk PB. Physiological chemistry. New York: McGraw-Hill; 1965.

21 Sentürk UK, Gündüz F, Kuru O, Aktekin MR, Kipmen D, Yalçin O, et al. Exercise-induced oxidative stress affects erythrocytes in sedentary rats but not exercise-trained rats. J Appl Physiol (1985). 2001 Nov;91(5):1999-2004.

22 Lippi G, Mercadanti M, Aloe R, Targher G. Erythrocyte mechanical fragility is increased in patients with type 2 diabetes. Eur J Intern Med. 2012 Mar;23(2):150-3.

23 Warren L. The thiobarbituric acid assay of sialic acids. J Biol Chem. 1959 Aug;234(8): 1971-5.

24 Jakubowska-Solarska B, Solski J. Sialic acids of young and old red blood cells in healthy subjects. Med Sci Monit. 2000 Sep-Oct;6(5): 871-4.

25 Olas B, Wachowicz B. Resveratrol and vitamin $\mathrm{C}$ as antioxidants in blood platelets. Thromb Res. 2002 Apr;106(2):143-8.
26 Basak A. Development of a rapid and inexpensive plasma glucose estimation by twopoint kinetic method based on glucose oxidase-peroxidase enzymes. Indian J Clin Biochem. 2007 Mar;22(1):156-60.

27 Buhl SN, Jackson KY, Graffunder B. Optimal reaction conditions for assaying human lactate dehydrogenase pyruvate-to-lactate at 25 , 30, and 37 degrees C. Clin Chem. 1978 Feb; 24(2):261-6.

28 Beutler E, Duran O, Kelley BM. Modified procedure for the estimation of reduced glutathione. J Lab Clin Med. 1963;61:882.

29 Da Cruz G. Use of bathocuproine for the evaluation of the antioxidant power in liquids and solutions. United States patent 6613577. 2003.

30 Avron M, Shavit N. A sensitive and simple method for determination of ferrocyanide. Anal Biochem. 1963 Dec;6(6):549-54.

31 Misra HP, Fridovich I. The role of superoxide anion in the autoxidation of epinephrine and a simple assay for superoxide dismutase. J Biol Chem. 1972 May;247(10):3170-5.

32 Aebi H. Catalase in vitro. Methods Enzymol. 1984;105:121-6.

33 Ohkawa H, Ohishi N, Yagi K. Assay for lipid peroxides in animal tissues by thiobarbituric acid reaction. Anal Biochem. 1979 Jun;95(2): 351-8.

34 Witko V, Nguyen AT, Descamps-Latscha B. Microtiter plate assay for phagocyte-derived taurine-chloramines. J Clin Lab Anal. 1992; 6(1):47-53.

35 Habeeb AF. Reaction of protein sulfhydryl groups with Ellman's reagent. Methods Enzymol. 1972;25:457-64.

36 Lowry OH, Rosebrough NJ, Farr AL, Randall RJ. Protein measurement with the Folin phenol reagent. J Biol Chem. 1951 Nov;193(1): 265-75.

37 Asha Devi S, Shiva Shankar Reddy CS, Subramanyam MV. Oxidative stress and intracellular $\mathrm{pH}$ in the young and old erythrocytes of rat. Biogerontology. 2009 Dec;10(6):659-69.

38 Kosower NS. Altered properties of erythrocytes in the aged. Am J Hematol. 1993 Mar; 42(3):241-7.
39 DeVenuto F, Wilson SM. Distribution of progesterone and its effect on human blood during storage. Transfusion. 1976 Mar-Apr; 16(2):107-12

40 D’Alessandro A, Zolla L. Biochemistry of red cell aging in vivo and storage lesions. Haematologica. 2013;7:389-96.

41 Xue Q, Yeung ES. Variability of intracellular lactate dehydrogenase isoenzymes in single human erythrocytes. Anal Chem. 1994 Apr; 66(7):1175-8.

42 Rizvi SI, Jha R, Maurya PK. Erythrocyte plasma membrane redox system in human aging. Rejuvenation Res. 2006;9(4):470-4.

43 Kumar D, Rizvi SI. Markers of oxidative stress in senescent erythrocytes obtained from young and old age rats. Rejuvenation Res. 2014 Oct;17(5):446-52.

44 Villalba JM, Navas P. Plasma membrane redox system in the control of stress-induced apoptosis. Antioxid Redox Signal. 2000;2(2): 213-30.

45 Ravikumar S, Hsieh C, Rajashekharaiah V. Prospects of curcumin as an additive in storage solutions: a study on erythrocytes. Turk J Med Sci. 2016 Apr;46(3):825-33.

46 Kurata M, Suzuki M, Agar NS. Antioxidant systems and erythrocyte life-span in mammals. Comp Biochem Physiol B. 1993 Nov; 106(3):477-87.

47 Soumya R, Vani R. CUPRAC-BCS and antioxidant activity assays as reliable markers of antioxidant capacity in erythrocytes. Hematology. 2015 Apr;20(3):165-74.

48 D’Alessandro A, Mirasole C, Zolla L. Haemoglobin glycation ( $\mathrm{Hb} 1 \mathrm{Ac}$ ) increases during red blood cell storage: a MALDI-TOF massspectrometry-based investigation. Vox Sang. 2013 Aug;105(2):177-80.

49 Astiz M, de Alaniz MJ, Marra CA. Antioxidant defense system in rats simultaneously intoxicated with agrochemicals. Environ Toxicol Pharmacol. 2009 Nov;28(3):465-73.

50 Dumaswala UJ, Zhuo L, Jacobsen DW, Jain SK, Sukalski KA. Protein and lipid oxidation of banked human erythrocytes: role of glutathione. Free Radic Biol Med. 1999 Nov;27(910):1041-9. 